\title{
Determination of the reference value of nitrogen mass fraction in the reference material of Polish soil
}

\author{
M. Mironiuk ${ }^{1} \cdot$ M. Barańska ${ }^{1} \cdot$ K. Chojnacka ${ }^{1} \cdot$ H. Górecki ${ }^{1}$
}

Received: 16 September 2015/ Accepted: 5 October 2016/Published online: 31 October 2016

(c) The Author(s) 2016. This article is published with open access at Springerlink.com

\begin{abstract}
Ensuring a traceability and meaningful of a measurements is one of the most important stages of each analysis, each measurement. It is especially important for measurement of the environmental samples, like soil, which is a very complex matrix. A certified reference materials (CRMs) should be routinely used for this purpose. The paper discusses the procedure for preparation of the soil samples for certification as CRM. As for agricultural reasons there is a growing demand for CRMs regarding a nitrogen mass fraction in the Polish soil, we prepared such a material and established the reference value with associated measurement uncertainty. Homogeneity and stability of the material were shown to be appropriate for the intended purpose. The presented approach can also be used in a process of manufacture of a laboratory reference material, which can be used for a routine quality control.
\end{abstract}

Keywords Quality control - Reference materials . Homogeneity $\cdot$ Stability $\cdot$ Reference value

\section{Introduction}

The use of reference materials (RMs) in analytical measurement is an important part of the reliability of the control of measurement results [1]. RMs can be used for

Electronic supplementary material The online version of this article (doi:10.1007/s00769-016-1240-x) contains supplementary material, which is available to authorized users.

M. Mironiuk

malgorzata.mironiuk@pwr.edu.pl

1 Faculty of Chemistry, Wrocław University of Science and Technology, Smoluchowskiego 25, 50-370 Wrocław, Poland calibration, quality control, method validation or assignment of values to other materials [2]. Reference materials should be properly selected to reflect the real sample. The content of analyte should be similar to the real content.

The most important features of the reference material are homogeneity and stability. Homogeneity is determined on the basis of comparison of the results for randomly selected samples. It is necessary to define within-sample and between-samples homogeneity. Minimum weight of the sample required for the measurements should be defined as well. The degree of homogeneity of the material ensures the recovery of the reference value with the associated uncertainty [1].

Stability of the RM depends on many factors that include the environmental factors (e.g., temperature, humidity, pressure), the way of the transportation and the storage conditions. Stability ensures that the value of the determined property is constant during the declared validity. Proceeding in accordance with the instruction of reference material provided by the producer is necessary to keep the homogeneity and stability [1,3].

Certified reference materials (CRM) have one or more specified property values with the associated uncertainty and reference to the measurement traceability [4]. For the certified matrix reference material such as soil, the certified reference value can be determined in different ways: by making measurements in a laboratory using a primary reference measurement procedure; based on interlaboratory comparisons using one or several methods or making measurements in a single laboratory using two or more methods used by two or more analysts. In any case, the reference value must be stated with the measurement uncertainty [3].

In the modern fertilizers consulting, to optimize fertilization, a mass fraction of nitrogen input is exactly adapted 
to the type of the cultivation and the mass fraction of this component in the soil. This optimization is possible only if the mass fraction of nitrogen in the soil each time before fertilization is determined. Dosage control is necessary for the proper cultivation of the plants. The value of the different forms of nitrogen in the soil is varied as a result of transformation associated with mineralization, nitrification, denitrification and leaching. The control of the mass fraction of nitrogen in the soil prevents adverse impacts on the environment of this element.

Laboratories, accredited by the Polish Centre for Accreditation (http://www.pca.gov.pl/en/), which have in their scope of accreditation the methods for the determination of nitrogen are required to maintain the measurement traceability according to the ISO/IEC 17025:2005 [5]. According to the Vocabulary in Metrology (VIM) [4], measurement traceability is defined as "property of a measurement result whereby the result can be related to a reference through a documented unbroken chain of calibrations, each contributing to the measurement uncertainty." In practice, ensuring the traceability means, among others, that the measurement equipment, which has a significant impact on the uncertainty of measurement, should be calibrated by the National Metrology Institutes and Designated Institutes or accredited calibration laboratories, comparison of individual measurement result relative to a higher-order standard and use of CRMs for the calibration of measuring instruments [6]. It is very important to have the CRM with a matrix similar to the one of the samples to be analyzed. The certified reference value of nitrogen content in commercially available CRMs for the soil matrix is an important selection criteria of CRM in environmental analysis.

In The International Database for CRMs, COMAR 105 CRMs of soil matrix are registered. Only a small part of CRMs of a soil matrix available in this base, Chinese production mainly, has the certified value of the nitrogen mass fraction [7]. Nitrogen is not on the list of the usually analyzed elements of The National Institute of Metrological Research (INRiM) in Italy as well [8].

High-quality RMs are demanding and costly to produce. It is not normally cost effective for laboratories to make their own RMs, so-called laboratory reference materials (LRMs) or in-house reference materials (IHRMs), which are prepared by users for their own purposes [9, 10].

The measurements were taken in framework of the project "Production and attestation of new types of reference materials crucial for achieving European accreditation for Polish industrial laboratories" attributed by the National Center for Research and Development in Poland. The aim of the project was to produce six CRMs, including soil. The soil was prepared for certification of aromatic hydrocarbons and polychlorinated biphenyls content by interlaboratory comparisons. For this project soil was taken from the areas of the Lower Silesia, Poland. Given the fact that nitrogen content in soil is an important parameter, part of the prepared material was used to provide the reference value of the total nitrogen mass fraction and associated measurement uncertainty.

\section{Experimental procedures}

The $150 \mathrm{~kg}$ of soil was collected from areas located in the vicinity of the chemical plant in Brzeg Dolny, Lower Silesia, Poland. The soil was air dried, homogenized and screened through a sieve of $250 \mu \mathrm{m}$ at first. Finally, the soil was brought to a grain size of $100 \mu \mathrm{m}$. In a subsequent step, the material was distributed into the amber glass bottles with the screw cap in $50 \mathrm{~g}$ portions. All bottles with soil were sterilized by electron beam radiation dose of $28 \mathrm{kGy}$. The elemental composition and water content were measured. The elemental composition (except nitrogen $-\mathrm{N}$ and carbon- $\mathrm{C}$ ) was determined after extraction in aqua regia with the microwave digestion system Ethos One, Milestone, Italy, using ICP-OES method (inductively coupled plasma-optical emission spectrometry) iCAP 6500 Duo, Thermo Scientific, USA and ICP-MS method (inductively coupled plasma-mass spectrometry) XSeries 2, Thermo Scientific, USA, according to the internal measurement procedures of the accredited laboratory (Accreditation number 696) [11]. N (total nitrogen) and C (total carbon) mass fraction were determined using the elemental analyses method with the analyzer Vario Macro Cube, Elementar Analysensysteme GmbH, Germany. The water content was determined using the gravimetric method (the sample was dried constant mass at $105{ }^{\circ} \mathrm{C}$ ), according to the ISO 11465:1993/AC1:1994 [12]. The elemental composition and water content of the soil sample are shown in Table 1.

The elemental composition and water content in airdried soil sample were typical for Polish soil [13].

The soil was packed into glass jars, each containing $50 \mathrm{~g}$ of the sample. Ten randomly selected jars, which were marked from F1 to F10, were selected for measurement.

The analyses and statistical evaluation were performed in Chemical Laboratory of Multielemental Analysis, Wrocław University of Technology, Poland, accredited by the Polish Centre for Accreditation (AB 696). Laboratory has in its scope of accreditation two measurement procedures of determination of the nitrogen mass fraction in the soil, which have been validated and are subjected to systematic control of measurement traceability in accordance with the requirements of ISO/IEC 17025:2005 [5]. Both these methods-determination of total nitrogen using titration method, according to the ISO 11261:1995 [14] 
Table 1 Elemental composition ${ }^{\mathrm{a}}$ and water content of the soil

\begin{tabular}{|c|c|c|}
\hline Element & Unit & $\begin{array}{l}\text { Mass fraction with } \\
\text { associated } \\
\text { uncertainty }^{b}\end{array}$ \\
\hline $\mathrm{Al}$ & & $1.8 \pm 0.4$ \\
\hline $\mathrm{Ca}$ & & $1.1 \pm 0.2$ \\
\hline $\mathrm{Fe}$ & & $0.95 \pm 0.19$ \\
\hline $\mathrm{K}$ & & $0.50 \pm 0.10$ \\
\hline $\mathrm{Mg}$ & & $0.29 \pm 0.06$ \\
\hline $\mathrm{Mn}$ & & $0.0380 \pm 0.0057$ \\
\hline $\mathrm{Na}$ & $\mathrm{g} /(100 \mathrm{~g})$ & $0.26 \pm 0.05$ \\
\hline $\mathrm{P}$ & & $0.10 \pm 0.02$ \\
\hline S & & $0.044 \pm 0.006$ \\
\hline $\mathrm{Si}$ & & $35 \pm 7$ \\
\hline $\mathrm{Ti}$ & & $0.132 \pm 0.026$ \\
\hline $\mathrm{C}$ & & $3.5 \pm 0.4$ \\
\hline $\mathrm{N}$ & & $0.27 \pm 0.03$ \\
\hline Co & & $2.9 \pm 0.4$ \\
\hline $\mathrm{Cr}$ & & $61 \pm 9$ \\
\hline $\mathrm{Cu}$ & & $27 \pm 4$ \\
\hline V & & $17 \pm 3$ \\
\hline $\mathrm{Zn}$ & & $180 \pm 27$ \\
\hline As & & $2.6 \pm 0.7$ \\
\hline $\mathrm{Ba}$ & $\mathrm{mg} / \mathrm{kg}$ & $526 \pm 79$ \\
\hline $\mathrm{Be}$ & & $<0.50$ \\
\hline $\mathrm{Cd}$ & & $0.84 \pm 0.13$ \\
\hline $\mathrm{Hg}$ & & $0.86 \pm 0.13$ \\
\hline $\mathrm{Ni}$ & & $18 \pm 3$ \\
\hline $\mathrm{Pb}$ & & $48 \pm 7$ \\
\hline Water content & $\mathrm{g} / \mathrm{g}$ & $0.0102 \pm 0.0003$ \\
\hline
\end{tabular}

${ }^{\text {a }}$ Values of elemental composition are based on the dried sample

b Expanded uncertainty of the standard method at confidence level 95\% (for $k=2$ )

(digestion and distillation system Büchi, Switzerland) and the determination of total nitrogen mass fraction by dry combustion, according to the ISO 13878:2002 [15] (elemental analyzer Vario Macro Cube)-were used to determine the nitrogen mass fraction in the soil samples. Analysis with the use of each of these methods was performed by two analysts.

\section{Between-samples homogeneity}

Evaluation of homogeneity aims to confirm that the differences between the individual samples are not systematic and are not statistically significant. The measurements were taken for all ten samples $(g-$ number of samples $=10)$. Two portions were prepared from each sample $(2 g=20)$. On the basis of the obtained results of the analysis, parameters for the statistical evaluation of homogeneity were determined, in accordance with ISO 13528:2005 [16]. The standard deviation for proficiency testing was estimated on the basis of a general model of Horwitz equation as:

$\hat{\sigma}=\frac{R \cdot \bar{X}}{100}$

where $R$ was described by Horwitz as:

$R=2^{(1-0.5 \cdot \log C)}$

where $\hat{\sigma}$ is the standard deviation for proficiency testing, $R$ relative standard deviation (RSD), $\bar{X}$ average value of measurements of ten samples of soil in duplicate, $C$ mass fraction (e.g., if the mass fraction is $10 \mathrm{mg} /(100 \mathrm{~g})$ then $\left.C=10 \times 10^{-3} \mathrm{~g} /(100 \mathrm{~g})=10^{-4}\right)$.

\section{Within-sample homogeneity}

In order to evaluate the influence of heterogeneity within a single sample, the evaluation of within-samples homogeneity was conducted. Among the ten selected samples, one jar was randomly selected. From the selected jar, two samples were collected. Two portions were prepared from each sample.

\section{Stability}

Stability was evaluated by performing the analysis of three randomly selected samples $(g=3)$, from the ten samples selected to evaluate homogeneity. Two portions were prepared from each sample $(2 g=6)$. The measurements were taken at scheduled intervals-after 2 and 4 weeks and 6 months. The procedure of the evaluation of stability was carried out on the basis of the guidelines of ISO 13528:2005 [16]. The same analytical methods as for the homogeneity check were applied. The measurements were taken under repeatability conditions.

In the next step, the impact of the storage temperature on the stability samples was examined. Three randomly selected samples were stored for 6 months in the controlled condition, at $+3{ }^{\circ} \mathrm{C}$ and $-24{ }^{\circ} \mathrm{C}$.

\section{Determination of the reference value}

The measurements were taken using two methods of measurement by two analysts. Each analyst performed two series of measurements, ten measurements for each series, both methods. For statistical evaluation 80 measurements were obtained. To detect outliers in a dataset, the Grubbs test was used, according to the ISO 5725-2:1994/AC1:2002 [17]. The reference value was estimated as the average of 80 measurements. 


\section{Uncertainty of the reference value}

On the basis of all performed measurements, the combined standard uncertainty of reference value was obtained by combining the individual standard uncertainties [18]:

$u_{\mathrm{c}}=\sqrt{\left(u_{\mathrm{av}}\right)^{2}+\left(u_{\mathrm{bsh}}\right)^{2}+\left(u_{\mathrm{wsh}}\right)^{2}+\left(u_{\mathrm{lts}}\right)^{2}+\left(u_{\mathrm{sts}}\right)^{2}}$

where $u_{\mathrm{c}}$ uncertainty of the reference value of nitrogen mass fraction, $u_{\mathrm{av}}$ uncertainty of determining of the average value of nitrogen mass fraction, $u_{\mathrm{bsh}}$ uncertainty associated with the between-samples homogeneity, $u_{\text {wsh }}$ uncertainty associated with the within-samples homogeneity, $u_{\mathrm{lts}}$ uncertainty associated with long-term stability, $u_{\text {sts }}$ uncertainty associated with short-term stability.

\section{Results and discussion}

The homogeneity and stability measurements were preceded by the comparison of the nitrogen mass fraction determined by the two different methods (titration method and dry combustion method). The measurements were taken by two analysts. The average of the nitrogen mass fraction determined using both methods is shown in Fig. 1.

In order to evaluate the influence of heterogeneity within a single sample for the result of the measurements, evaluation of the within-sample homogeneity was conducted. The results of the nitrogen mass fraction using both methods conducted by two analysts are shown in Fig. 2.

In the next step, the between-samples homogeneity and the within-sample homogeneity of the soil samples were evaluated. The obtained values of the derived parameters are shown in Table 2. Adopted criterion of homogeneity: $S_{\mathrm{S}} \leq 0.3 \hat{\sigma}$. Additional data are accessible as Electronic Supplementary Material (ESM).

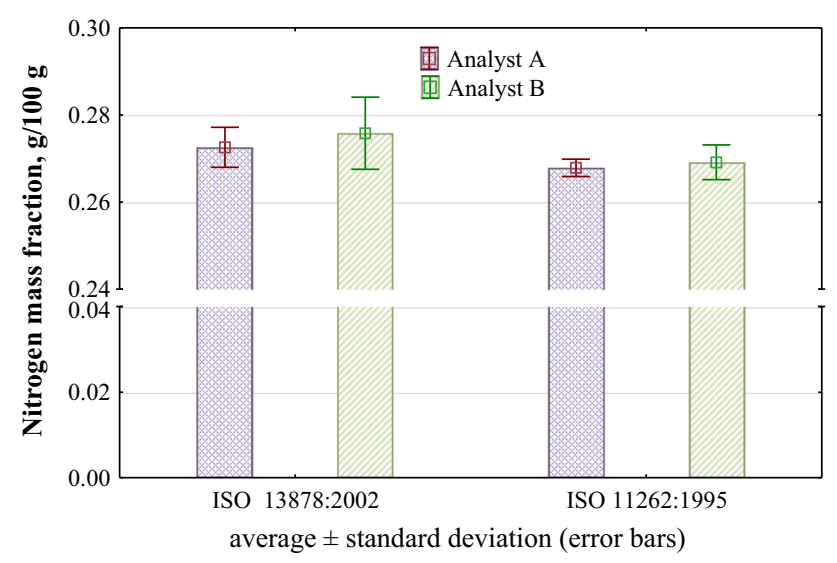

Fig. 1 Average of the nitrogen mass fraction determined by the Kjeldahl method and dry combustion method

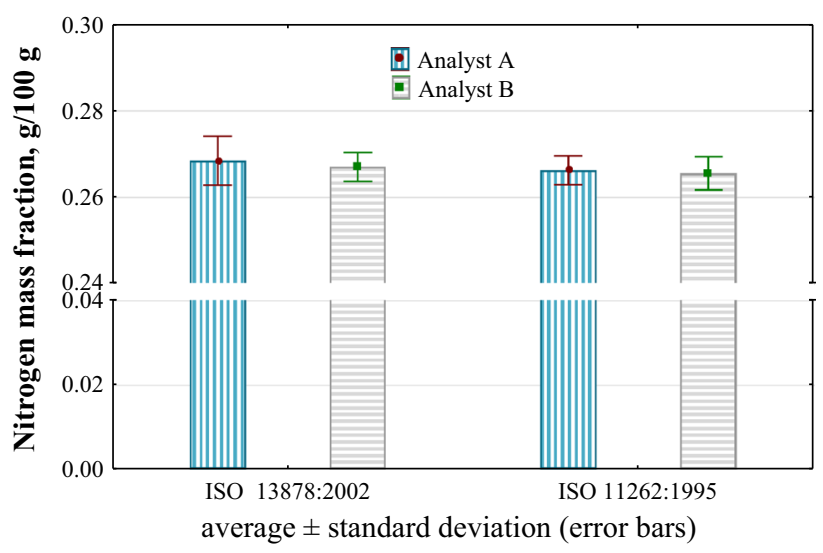

Fig. 2 Average of the nitrogen mass fraction within the single sample

Results of the evaluation of the homogeneity showed that the standard deviation between the samples was less than the criterion of homogeneity check; therefore, the given samples can be considered as sufficiently homogeneous.

In the case of the standard deviation between the samples collected from the same jar, received as a result of the measurement of the within-sample homogeneity, the criterion of homogeneity was also met; therefore, the given samples can be considered as sufficiently homogeneous within one sample.

It should be remembered, that the material is homogeneous for a specific mass of the sample, for which the homogeneity was verified. The material can be homogeneous when a large mass of material is used for analysis, but heterogeneity may be detectable in small masses of sample [19]. The minimum weight of sample recommended for the use should be specified on the reference material certificate. All the measurements were taken on the soil samples with the mass of $200 \mathrm{mg}$, therefore for the given material the samples minimum measurement portion having the mass of $200 \mathrm{mg}$.

On the basis of the results, the evaluations of the shortterm and long-term stability were made. Adopted criterion of stability: $|\bar{X}-\bar{Y}| \leq 0.3 \hat{\sigma}$. The results are shown in Table 3 .

In the next step, the impact of the storage temperature on the stability of the samples was examined. Adopted criterion of stability: $|\bar{X}-\bar{Y}| \leq 0.3 \hat{\sigma}$. The results are shown in Table 4.

The stability of the material was verified after the homogeneity of the soil samples was confirmed. The stability criterion for the samples was met. The obtained results indicated that the material was stable under the studied conditions. The material can be stored in the fridge and can be frozen.

The reference value was determined based on the measurement results of the ten soil samples. The average 
Table 2 Homogeneity of nitrogen mass fraction, g/(100 g)

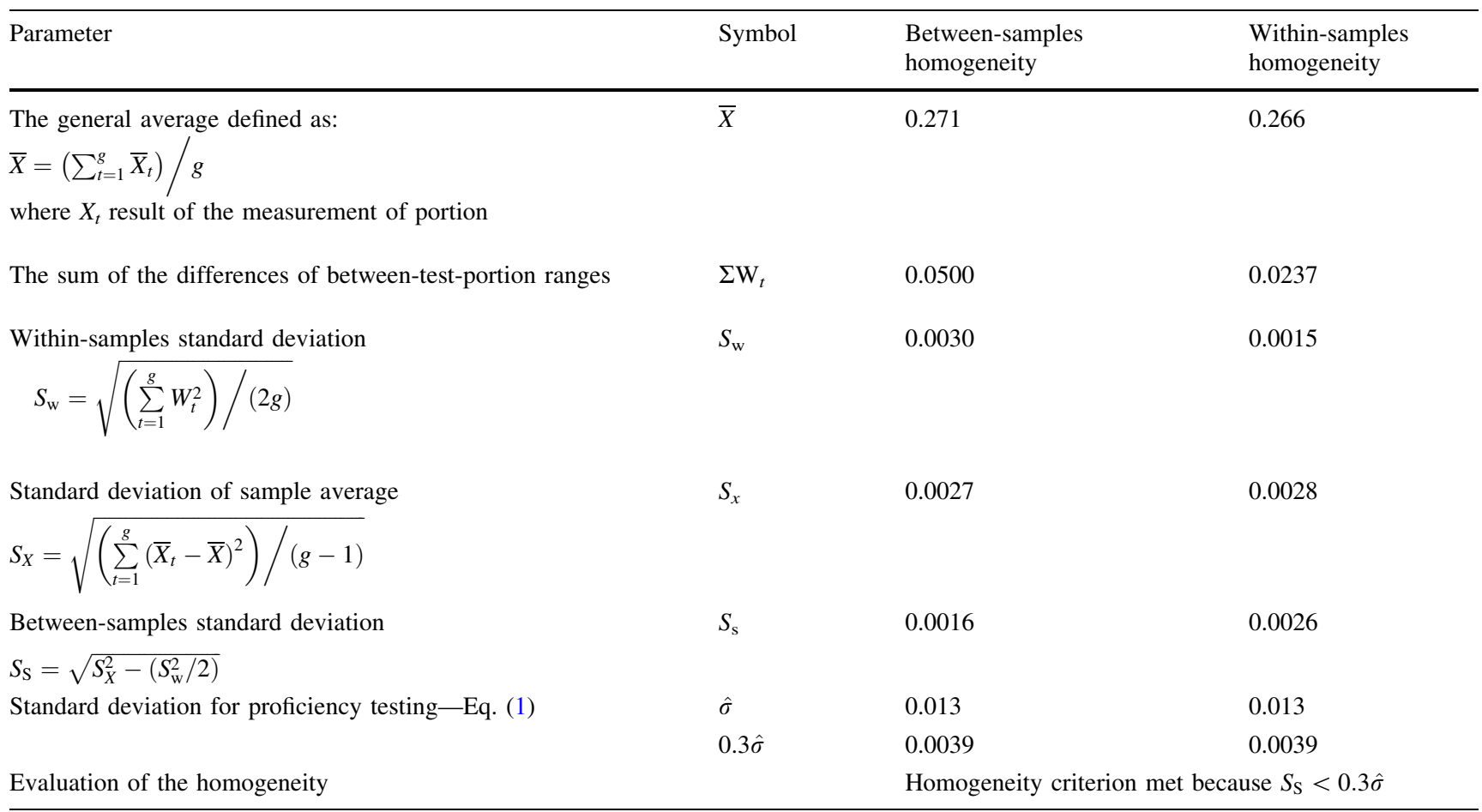

Table 3 Short-term and long-term stability

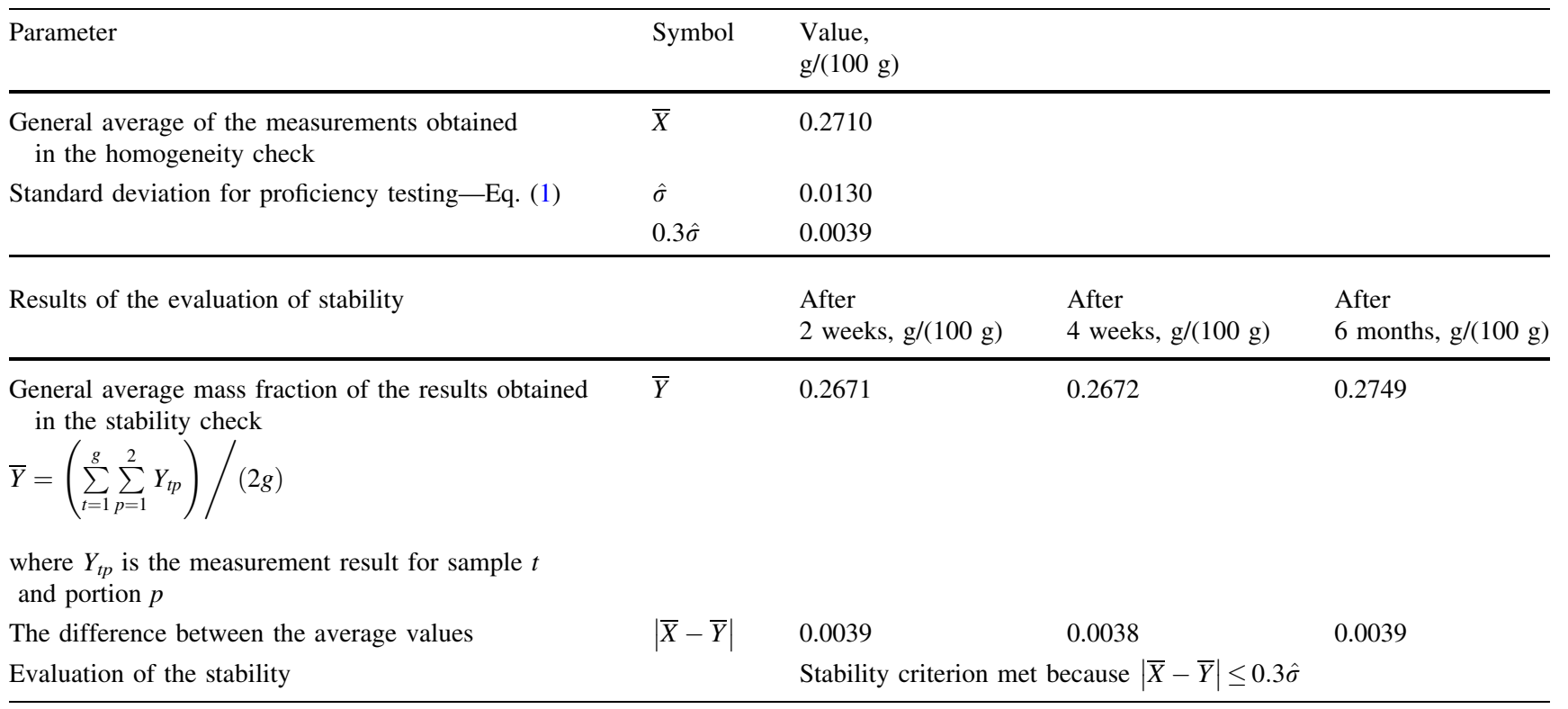

values of the measurements are shown in Table 5, separately for the each analyst and each measurement method. Additional data are accessible in the ESM.

The average nitrogen mass fraction determined using the modified Kjeldahl method was $0.266 \mathrm{~g} /(100 \mathrm{~g})$, and the thermo-conductometric method $0.268 \mathrm{~g} /(100 \mathrm{~g})$, what represents the difference at the level of approximately $0.8 \%$. The same two methods were used by Gawlik et al.
[20] to determine the mass fraction of total nitrogen in the study of certification of the European Reference Soil Set, and comparable results were achieved. It might confirm usefulness and relevance of use of these two methods for the analysis of the total nitrogen in the soil samples.

The reference values of the nitrogen mass fraction in the given material were developed from the analytical data obtained from the analysis performed with the two, 
Table 4 Influence of temperature $(T)$ on the stability of the soil samples

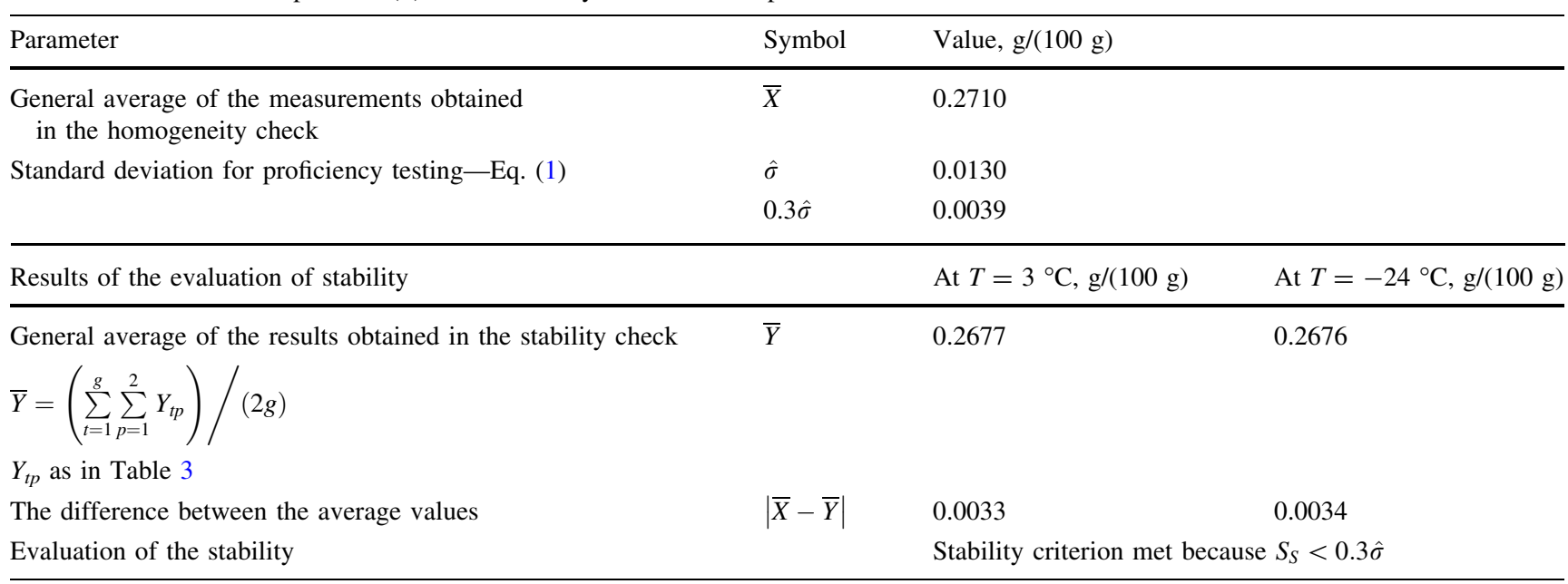

Table 5 Reference value of the nitrogen mass fraction in the soil sample

Average value of nitrogen mass fraction, $\mathrm{g} /(100 \mathrm{~g})$

\begin{tabular}{lll}
\hline & Analyst A & Analyst B \\
\hline According to ISO 13878 & 0.266 & 0.266 \\
According to ISO 11261 & 0.268 & 0.267
\end{tabular}

The reference value of nitrogen mass fraction in the soil sample is $0.267 \mathrm{~g} /(100 \mathrm{~g})$

independent methods, used by two analysts. According to the ISO Guide 35:2006, this approach is technically correct and reasonable [21]. In the given soil sample, the reference value was set at $0.2667 \mathrm{~g} /(100 \mathrm{~g})$ of the nitrogen. According to the latest data published by Chief Inspectorate of Environmental Protection in Poland, the nitrogen mass fraction in the Polish soils is at the range of $0.04-0.41 \mathrm{~g} /(100 \mathrm{~g})$ [22]. The total nitrogen mass fraction in the given sample was therefore typical for Polish soils. This confirmed that the natural matrix of the CRM was prepared from the material found in nature [13].

In the final stage of the research, the uncertainty of the reference value was determined. The standard combined uncertainty was estimated as the root of sum of squares of the standard uncertainties of each component, according to Eq. 3. The results are shown in Table 6.

The reference value has the standard uncertainty that depends on the method that is used to derive it [19]. As the Botha et al. [2] mentioned, there is no general approach for the evaluation of uncertainty for all measurement procedures and materials. In our measurements, the uncertainty estimated for the reference value of the nitrogen mass fraction was $7.5 \%$ and does not differ from the uncertainty in the CRMs available on the market, e.g., uncertainty at the range of $7.7 \%$ for CRM
Table 6 Uncertainty of the reference value of the nitrogen mass fraction in the soil sample; all data in $\mathrm{g} /(100 \mathrm{~g})$

\begin{tabular}{ll}
\hline Standard uncertainty ${ }^{\mathrm{a}}$ of the components & \\
Determining of the average value, $u_{\mathrm{av}}$ & 0.0037 \\
Between-samples homogeneity, $u_{\mathrm{buh}}$ & 0.0027 \\
Within-samples homogeneity, $u_{\mathrm{wuh}}$ & 0.0028 \\
Long-term stability, $u_{\mathrm{lts}}$ & 0.0061 \\
Short-term stability, $u_{\mathrm{sts}}$ & 0.0052 \\
Combined standard uncertainty, $u_{\mathrm{c}}$ & $\mathbf{0 . 0 1 0}$ \\
Expanded uncertainty & $\mathbf{0 . 0 2 0}$ \\
Reference value of the nitrogen mass fraction & $\mathbf{0 . 2 6 7} \pm \mathbf{0 . 0 2 0}$
\end{tabular}

${ }^{a}$ Expressed as the standard deviation of the result obtained using both measurement procedures

b Coverage factor $k=2$

NCS DC73321; $8.7 \%$ for NCS ZC73001 or $9.4 \%$ for NCS DC73325 [6].

\section{Conclusions}

Based on the results of the evaluation of homogeneity and stability of the soil samples, it was found that the given material can be considered as the candidate for CRM. The use of two independent measurement procedures in terms of repeatability ensured the high level of the quality control. The presented procedures for evaluation of the homogeneity, stability and determination of the reference value with the uncertainty can be used for preparing laboratory reference materials (LRMs). Such LRMs can be used for routine quality assurance of soil samples, which is necessary to evaluate properties of the new fertilizers formulations. In this way, problem of unavailability of some matrix on the market of CRMs can be solved. It is economically justified as well. 
Acknowledgements This project is financed in the framework of grant entitled: "Production and attestation of new types of reference materials crucial for achieving European accreditation for polish industrial laboratories" attributed by the National Center for Research and Development. Project was supported by Wroclaw Centre of Biotechnology programme, The Leading National Research Centre (KNOW) for years 2014-2018.

Open Access This article is distributed under the terms of the Creative Commons Attribution 4.0 International License (http:// creativecommons.org/licenses/by/4.0/), which permits unrestricted use, distribution, and reproduction in any medium, provided you give appropriate credit to the original author(s) and the source, provide a link to the Creative Commons license, and indicate if changes were made.

\section{References}

1. Bulska E (2008) Chemical metrology. The art of measurement. Malamute Publishing, Warsaw (in Polish)

2. Botha A, Ellison S, Linsinger T, Van der Veen A (2013) Outline for the revision of ISO Guide 35. Accred Qual Assur 18:115-118

3. Konieczka P (2012) The use of certified reference materials-a necessary condition for the reliability of measurement results. Polish Club of Testing Laboratories Pollab Publishing, Warsaw (in Polish)

4. JCGM 200 (2012) International vocabulary of metrology-basic and general concepts and associated terms (VIM), 3rd edn. 2008 version with minor corrections

5. ISO/IEC 17025 (2005) General requirements for the competence of testing and calibration laboratories. International Organization for Standardization (ISO), Geneva

6. ILAC-P10:01 (2013) ILAC policy on the traceability of measurement results. International Laboratory Accreditation Cooperation (ILAC), Australia

7. COMAR (2016) International database for certified reference materials. http://www.comar.bam.de/en/. Accessed 4 July 2016

8. Durbiano F, Amico Di Meane E, Boveri CH, Giordani L, Sega M (2011) INRiM contributions in the characterization and certification of reference materials. Measurement 44:1381-1388
9. EA-4/14 INF:2003 The selection and use of reference materials

10. Zschunke A (2000) Reference materials in analytical chemistry. A guide for selection and use. Springer, Berlin

11. Research procedures of the Chemical Laboratory of Multielemental Analysis, Wrocław, Poland (2014) Scope of accreditation. http://www.pca.gov.pl/en/. Accreditation Number: AB 696

12. ISO 11465: 1993/ACl:1994 Soil quality. Determination of dry matter and water content on a mass basis. Gravimetric method. International Organization for Standardization (ISO), Geneva

13. Main Inspectorate of Environmental Protection, Poland. http:// www.gios.gov.pl/pl. Access 16 Sept 2015

14. ISO 11261:1995 Soil quality. Determination of total nitrogen. Modified Kjeldahl method. International Organization for Standardization (ISO), Geneva

15. ISO 13878:2002 Soil quality. Determination of total nitrogen content by dry combustion ("elemental analysis"). International Organization for Standardization (ISO), Geneva

16. ISO 13528:2005 Statistical methods for use in proficiency testing by interlaboratory comparisons. International Organization for Standardization (ISO), Geneva

17. ISO 5725-2:1994/AC1:2002 Accuracy (trueness and precision) of measurement methods and results. Part 2: basic method for the determination of repeatability and reproducibility of a standard measurement method. International Organization for Standardization (ISO), Geneva

18. NIST Technical Note 1297, Guidelines for evaluating and expressing the uncertainty of NIST measurement results (1994)

19. Schiller SB (1996) Statistical aspects of the certification of chemical batch SRMs. NIST Special Publication 260-125

20. Gawlik BM, Lamberty A, Pauwels J, Blum WEH, Mentler A, Bussian B, Eklo O, Fox K, Kordel W, Hennecke D, Maurer T, Peerin-Ganier C, Romero-Taboada E, Szabo G, Muntau H (2003) Certification of the European reference soil set (IRMM-443EUROSOILS). Part II. Soil-pH in suspensions of water and $\mathrm{CaCl}$. Sci Total Environ 312:33-42

21. ISO Guide 35:2006 Reference materials - general and statistical principles of certification

22. Institute of Soil Science and Plant Cultivation State Research Institute in Puławy (Poland) 2012. Chemistry monitoring of arable soils in Poland 2010-2012, Puławy, Poland. http://www.gios.gov. pl/zalaczniki/artykuly/Monitoring_sprawozd_koncowe2.pdf. Access 27 Jan 2015 